\title{
International Geoscience Programme (IGCP)
}

\section{Guidelines}

2006 Call for Project Proposals (31 July 2006)

The International Geoscience Programme (IGCP) is launching its 2006 call for project proposals. The proposal guidelines and application forms were updated in order to bring them in line with the requirements of the strategic plan of UNESCO and IUGS (International Union of Geological Sciences), the two co-sponsoring partners. New IGCP projects shall reach out beyond the earth science community to decision-makers, government planners and policy-makers. Moreover, the new IGCP projects shall be more interdisciplinary in nature and give particular attention to the following topics: Geoscience of the Water Cycle, Geohazards, Earth Resources, Global Change and Life Evolution, The Deep Earth and other relevant topics in basic/applied geoscience.

\section{Content}

1. Purpose and objectives of the IGCP

2. Operational policy

3. Topics for IGCP project proposals

4. Project proposals

5. Project structure and activities

5.1. Leadership

5.2. Merging projects

5.3. Extension of project activities

6. Young Scientists Projects

7. Funding

8. Reports

9. Publications and acknowledgement

10. Experience from successful IGCP projects

11. Sample IGCP projects emphasizing societal relevance

12. Example of an especially successful IGCP project emphasizing basic research

\section{Attachment}

Project proposal form

\section{Purpose and objectives of the IGCP}

The International Geoscience Programme (IGCP) - formerly International Geological Correlation Programme-is a joint endeavor of UNESCO (United Nations Educational, Scientific and Cultural Organization) and IUGS (International Union of Geological Sciences).

The primary aims of IGCP are to facilitate international collaboration amongst scientists from around the world in research on geological problems, particularly between those individuals from more industrialized and those from developing countries. Through longterm joint research efforts, meetings, field trips, and workshops, IGCP aims to promote the use of geosciences in global issues including, but not limited to, sustainable development, the health and safety of humanity and the reduction of the adverse effects of natural disasters and resource extraction.

IGCP is an international and multidisciplinary programme. It covers different fields in the Earth Sciences and complements other UNESCO and IUGS scientific programmes. It supports interaction with disciplines such as hydrological, ecological, oceanographic, atmospheric and biological sciences. IGCP has proven to be a very successful and cost-effective way of promoting sustainable development by enhancing geoscientific knowledge and expertise in developing countries.
IGCP pursues four broad objectives:

- improving our understanding of the geoscientific factors affecting the global environment in order to improve human living conditions;

- developing more effective methods to find and sustainably exploit natural resources of minerals, energy and groundwater;

- increasing understanding of geological processes and concepts of global importance, including an emphasis on socially relevant issues; and,

- improving standards, methods and techniques of carrying out geological research, including the transfer of geological and geotechnological knowledge between industrialized and developing countries.

\section{Operational policy}

The objectives of IGCP are met through individual projects. The number of active projects in any given year depends on the current priorities of UNESCO and IUGS, the availability of funds, the success and progress of existing projects and the quality and merit of newly submitted proposals.

Background: The success of the Programme and individual projects is the result of the dedication of project leaders and the enthusiasm, support, and participation of geoscientists from around the world. Projects often build upon existing activities within participating countries, and attract additional funds from governmental and other agencies.

Project proposers should identify the possible societal relevance of their work, address the challenge of capacity-building in developing countries, emphasize education and training, including a focus on under-represented groups (e.g. youth, women, ethnic minorities).

Duration: IGCP projects are approved for a period not exceeding five years. Individual projects are reviewed annually after the second year and may be terminated following review for their poor performance.

Financial support: The annual allocation of support for each project depends upon its quality and, for an already funded project, upon its performance during the previous year. The financial support provided annually by UNESCO and IUGS for IGCP projects covers part of the costs of organizing and managing research, meetings, and workshops, related to the project, as well as to facilitate participation 
by scientists from developing countries. These limited funds provide 'seed money' to assist in the acquisition of additional funds from other sources. Past experience indicates that successful IGCP projects are able to secure significant additional funding from other sources. The actual amount of funding provided annually all IGCP projects reflects the collective decisions of UNESCO and IUGS.

Evaluation: IGCP projects must successfully meet the following criteria:

- focus on high-quality science relevant to the scientific objectives of the IGCP;

- meet a need of international importance and societal relevance;

- emphasize interdisciplinary cooperation;

- constitute international participation including scientists from developing countries;

- demonstrate potential for both long-term and short-term geoscientific and/or societal benefits;

- explicitly acknowledge the sponsorship of UNESCO, IUGS, and IGCP; and,

- promote global geoscience visibility. For example, through the publication of scientific results using internationally recognized journals or other media ${ }^{1}$.

UNESCO and IUGS jointly appoint members to the IGCP Scientific Board. Individual IGCP proposals and Annual Reports are assigned to thematically appropriate members of the Scientific Board for initial evaluation of their scientific merit and relevance to IGCP objectives. Select members of the IGCP Scientific Board collectively consider the initial evaluations and prioritize applications for funding.

\section{Topics for IGCP project proposals}

IGCP welcomes proposals on the following topics:

- topics of particular interest to IGCP (as outlined in the following),

- topics defined annually by UNESCO and IUGS,

- other relevant topics in fundamental and applied geoscience.

\section{Topics of particular interest to IGCP}

\section{- Geoscience of the Water Cycle}

Life on Earth depends on water and its sustainable use is crucial for continued human existence. Earth's water resources include surface/ground water, ocean water, and ice. The study of Earth's water involves understanding and managing both surface and groundwater systems, including sources, contamination, vulnerability and history of water systems.

- Geohazards: Mitigating the risks

Geohazards include earthquakes, volcanic activity, landslides, tsunamis, floods, meteorite impacts and the health hazards of geologic materials. Geohazards can range from local events such as a debris slide or coastal erosion to events that threaten humankind (e.g., supervolcano eruption or meteorite impact). Earth scientists undertake research to better understand such hazards and contribute to risk reduction.

- Earth Resources: Sustaining our society Earth resources include minerals, hydrocarbons, geothermal energy, air, and water. The future well-being of society depends on sustainable use of these resources. The environmentally responsible exploitation of these resources is a challenge for geoscience research. The progress of technological development is equally bound to this premise.

- Global Change and Evolution of Life: Evidence from the geological record

Changes in the Earth's climate and of life on Earth are preserved in the rock record. Ice and dust records, terrestrial and ocean sediments, and sequences of fossil plant and animal assemblages all comprise parts of this record. Life has impacted Earth's atmosphere, oceans, and land surface. Several major extinctions have punctuated Earth's history, associated with dramatic environmental and ecosystem change. Past environmental lessons shed light on present and future challenges.

- The Deep Earth: How it controls our environment The Earth's surface, including our habitable environment, is a product of, and controlled by deep Earth processes. The study of this environment (ranging from changes in the Earth's magnetic field to plate tectonics) using for example, geophysical and geodynamical techniques, enhances our understanding of the working of System Earth.

\section{Topics defined annually}

These are specific topics identified cooperatively by UNESCO, IUGS and the IGCP Scientific Board that are perceived to be of timely relevance in any given year.

\section{Other relevant topics in fundamental and applied geosciences}

The IGCP encourages submission of project proposals in all aspects of the geosciences, provided they meet the requirements outlined above ("Evaluation" part of Section 2-Operational Policy).

\section{Project proposals}

IGCP project proposals may be submitted by individual scientists or by a group of scientists ${ }^{2}$. The IGCP Scientific Board is ready to advise project leaders, regarding the scientific quality, content, scope, viability, budget and relevance of potential project proposals (e.g., advice regarding the inclusion of other qualified scientists, bridging to other initiatives, outputs).

Assessments of proposals for new IGCP projects (and the Annual Reports of ongoing projects) are conducted once a year by selected representatives of the IGCP Scientific Board, usually during the first half of February. Assessments are based upon the criteria and objectives of IGCP (e.g. the scientific potential and feasibility of proposals, adherence to the overall goals of IGCP, qualifications of the proposers, scientific progress of the projects, significance of their results, adherence to an approved budget and so on). Projects are ranked into one of three funding levels: high, medium, or low.

The deadline for submission and receipt of new project proposals to the IGCP Secretariat is $\mathbf{1 5}$ October. Each project leader must include a letter of endorsement from his or her respective IGCP or IUGS National Committee. The IGCP Secretariat will promptly inform proponents of the decisions regarding individual proposals.

Proposal forms are available from the IGCP Secretariat or through the following website:

http://www.unesco.org/science/earth/igcp.shtml

\footnotetext{
${ }^{1}$ Including high-quality, high-impact journals published both by not-for-profit and for-profit organizations. Subscriptions for the former characteristically cost less.

${ }^{2}$ It is hoped that participating individuals from countries without an Active Adhering Organization in IUGS would work for establishment or renewal of such a relationship, as appropraite, in order to benefit from the full scope of IUGS's offerings and to enhance IUGS's ability to support future IGCP projects.
} 


\section{Young Scientist Projects}

The IGCP Young Scientist Project aims at fostering international cooperation between prospective young scientists from developing and developed countries early in their careers. It is expected that this will recruit and train young scientists to establish future cooperative projects. Proposals and projects should follow these guidelines:

- Proposers should be within 10 years of their $\mathrm{PhD}$.

- Proposers should provide a CV and include a copy of at least one international peer-reviewed publication in their field.

- Proposers are encouraged (but not required) to find an experienced scientist as advisor to help guiding the project.

- Proposers need to demonstrate an affiliation to a research institute, university, geological survey, or equivalent organization for the duration of the project.

- Projects may, but do not need, to be linked to an existing IGCP project.

- The project duration is three years; the project should involve at least three young scientists from a minimum of two countries. The principal proposer must be from a developing country.

- The Young Scientist Project will be awarded a maximum of US $\$ 5,000$ per year.

- These funds are provided to support

- field meetings with at least five participants, which should include the group leaders,

- travel to IGCP-organized or any other international scientific conference,

- participation in training courses,

- research equipment (max. 20\% of the allocated funds).

\section{Project structure and activities}

\subsection{Leadership and Responsibilities}

Project leadership is identified as per the proposal. IGCP projects preferably should be managed by more than one leader, ideally including leaders and co-leaders from less developed countries. The project leaders are the primary liaison with the IGCP Secretariat, UNESCO, and IUGS.

Successful IGCP projects clearly define their working structure, leadership and work plan emphasizing the internal interdisciplinary nature.

Scientists participating in a project on an individual basis should keep their respective National IGCP and IUGS Committees, as well as National Commissions to UNESCO informed about progress.

\subsection{Merging projects}

It may happen that project proposals aim at similar problems or are closely related to those dealt with in existing projects. In such cases, the Scientific Board may recommend project merger to project leaders. The project structure should therefore be flexible enough to incorporate new participants and new directions for research as appropriate on an equitable basis.

\subsection{Extension of project activities for a sixth year}

At the end of five years, the IGCP Scientific Board may recommend to IUGS and UNESCO a one-year extension for certain projects. Such IGCP "On Extended Term" (O.E.T.) projects function without additional funding from IGCP. Such projects will continue to provide the IGCP Secretariat and IUGS Permanent Secretariat with a brief annual report and copies of all publications. They will retain the right to use the IGCP logotype.

\section{Funding}

All new and ongoing IGCP projects are evaluated annually, after the second year of activity, by the IGCP Scientific Board according to their progress and scientific merit (low-medium-high). The IGCP Scientific Board submits a composite prioritized list of the projects to the IGCP Secretariat. The final allocation of available funds to individual projects is subsequently determined collaboratively by UNESCO and IUGS.

Payments will be made through the IUGS Treasurer, or UNESCO field offices, upon approval and endorsement of the complete workplan by the IGCP Secretary. To be given financial support, project leaders are required to submit to the IGCP Secretariat, no later than two months before the date of the execution of the project meeting, a document containing detailed information on the annual workplan; date and venue of meeting(s); name, institute, and country of participants to be given financial support; bank data for money transfer.

All new projects receive 'Medium' level funding for the first two years. Currently the average funding level for IGCP projects ranges between US\$5000 and US\$10,000.

Certain conditions must be met in order to conform to the funding requirements:

1. The allocated sum should be used strictly for travel and/or subsistence costs only of invited participants in the workshops/meetings sponsored by the project. The allocated sum should not be used exclusively to cover the travel expenses of Project Leaders.

2. Secretariat/administrative expenses should not exceed ten per cent of the total allocation.

3. Publications are not covered by the fund allocation.

4. As a rule, funds allocated for the given year cannot be carried over to the following year.

5. All project-related outputs (publications, presentations, etc.) must clearly show the logo of the IGCP and that UNESCO and IUGS are the financial sponsors. Report.

A detailed financial statement must accompany the Annual

\section{Reports}

Annual Report forms are sent out to project leaders by the IGCP Secretariat. The Annual Report (in grammatically correct English and using the IGCP formats) is the basis for the assessment of an IGCP project and the subsequent allocation of funds (high, medium, low). Project leaders must submit their Annual Report electronically to the IGCP Secretariat and simultaneously to the IUGS Permanent Secretariat before 15 December. Failure to submit an Annual Report before the deadline will result in automatic termination of the project. Under no circumstances are delays to this deadline permitted.

Copies of additional relevant materials (books, maps, etc.) may be submitted by regular post or courier directly to the IGCP Secretariat, to be received before 15 December. Annual reports and other documentation are used for the scientific evaluation by the IGCP Scientific Board.

The Annual Report provides a concise account of activities for the preceding year including, but not limited to, events (e.g. meeting theme, date, location, number of participants, etc.), research activities (e.g. field and laboratory studies, etc.), training (e.g. workshop and short course topics, location, date, etc.), details of proposed budget and expenses (names of recipients, receipts), publications and other accomplishments and future plans. Project leaders should clearly document and provide examples how IGCP, UNESCO, and IUGS were recognized and credited in all IGCP project-related activities. There should be a clear focus on scientific achievements in the annual reports. Meetings and conferences are not considered as scientific achievements. 
The Annual Reports provide the basis for summaries used by the IGCP Secretariat, UNESCO, and IUGS for other purposes benefiting the global geoscience community and will be used for publication in the e-format of Geological Correlation.

Upon termination of a project after its final year of activity, leaders must submit a Final Report that is concise, grammatically correct, and detailed. In addition to scientific achievements, the final report should show how the work plan has been implemented and indicate any practical applications of the conclusions.

\section{Publications and acknowledgement}

The success of an IGCP project should be clearly illustrated by presentation of its achievements at international meetings and through publication in internationally recognized media. Apart from the Annual Reports, it is expected that the results of IGCP projects will be published in the regular media, as either monographs, books, correlation charts, etc. or as reviews and individual papers in peerreviewed international scientific journals. Ideal outlets include, for example, the IUGS journal Episodes for general reporting of meetings and results to disseminate the work of a project and the IUGS Geological Society of London book series for full monographs. Project leaders should strive to involve TV, Internet, and press media to disseminate findings that are of interest to the general public.

All publications resulting from IGCP projects must include the IGCP logo. All IGCP projects must clearly recognize and acknowledge the support of IGCP and, as mentioned above, the financial support of UNESCO and IUGS. Successful IGCP projects should maintain a regularly updated website, linked to the IGCP homepage and others (e.g. IUGS). It is mandatory that the IGCP Secretariat receives at least one copy of each publication for its archive.

\section{Experience from successful IGCP projects}

Experience shows that successful projects have the following characteristics:

- Identify and focus clearly on specific scientific problems.

- Recognize timely problems that include new ideas, new techniques and newly discovered evidence and results.

- Provide a vehicle for uniting field, laboratory and theoretical studies.

- Provide a basis for future studies as well as education and training.

- Provide high quality and internationally respected leadership. Leaders are committed, active, effective, productive and genuinely interested in equitable collaboration.

- Identify and integrate "basic" and "applied" aspects of the project.

- Disseminate timely results through international meetings and publications.

- Are characterized by international leadership and member participation; especially including individuals from developing countries.

- Establish a project website that is regularly updated and linked to the IGCP homepage.

See examples of successful projects in Sections 11 and 12.

\section{Sample IGCP Projects Emphasizing Societal Relevance}

The following summaries of existing IGCP projects emphasizing societal relevance are provided to serve as a guide for individuals preparing applications for IGCP projects.

\section{Project No. 455 - Basement Volcanoes Interplay and Human} Activities (2001-2005) (A. Tibaldi, Italy)

The project focuses on the role of basement lithologies in gravitational stability of large volcanic structures. Important aspects are 1) the study of volcanism and associated geohazards, especially the mitigation of volcanic collapse, eruptions, landslides and earthquakes; and 2) development and dissemination of techniques and skills to mitigate the effects of volcanic eruptions. . The results of the project will include: 1) a database performing and centralizing previously scattered statistical analyses of appropriate geotechnical, petro-geochemical, and geochronological techniques; 2) investigation of recent and active volcanic areas, as well as older, deeply eroded volcanic remnants, in circum-Pacific convergent zones the East African rift; oceanic and continental intra-plate volcanic regions of the Atlantic and Asian, and Antarctic regions; the complex plate boundary sectors in the Mediterranean area; and hazard maps in densely populated target areas. The project will develop a catalogue of standardised observations related to the evaluation of basement-volcano stability, which could then be used as a reference for less well studied volcanoes. Societal aspects of the project embrace also applications useful to geothermal energy, and mineral and water resource exploration.

Project No. 487 - Seismic Microzoning of Latin American Cities (J. L. Alvarez Gómez, Cuba, A. Giesecke, Peru, G. F. Panza, Italy)

The project is, to some extent, a successor to the recently completed RADIUS, a UN International Decade for Natural Disaster Reduction (IDNDR) programme. It addresses pre-disaster work: prediction of expected earthquake effects in important cities of Latin America, in order to reduce the possible impact of great earthquakes. This prediction consists of two parts; 1) determining the most probable earthquake (or in some cases the bigger one) that can affect a city, i.e., seismic hazard assessment (probabilistic or deterministic) expressed in values of expected seismic effects for a particular kind of soil at a regional scale; 2) evaluation of the variation throughout a city located in a sedimentary basin, where local incremental effects are commonly present. The first part is at present well known in the Latin American region, as a result of more than 20 years of seismic hazard assessment studies at national or regional scale. The results of these studies form the initial base for this project. The second part is more complicated, it falls in the field which it is known as "seismic microzoning", a kind of work that normally involves big research teams, the use of expensive equipment and long time of registration of local earthquakes or microseisms. Because of the cost of this kind of research such work has been more limited than desired.

\section{Project No. 490 - Environmental Catastrophes (2003-2007) \\ (S. Leroy and I. Stewart, United Kingdom)}

The project focuses on interdisciplinary investigations of Holocene geological catastrophes, which are of importance for civilizations and ecosystems. Presently, there is no nationally or internationally equivalent group dealing with this topic. Joining the efforts of the several international organizations such as IUGS, the International Quaternary Organization (INQUA), UNESCO, and the International Geosphere-Biosphere Programme (IGBP) will create a new synergy. The project is concerned with environmental events since the beginning of the Holocene (the last 11,500 years) excluding the influence of the glacial-interglacial cycles. Three time scales will be considered: (1) the Holocene when major natural hazards are mostly known from sedimentary records; (2) the last 5-4000 years for 
which we have written documents; (3) the last couple of centuries with instrumental records. Importantly, the project will examine how quickly ecosystems and civilisations are able to recover from catastrophic events. With the growing recognition that major natural events can have abrupt global impacts, this project is a timely opportunity to assess the sensitivity of modern society to extreme natural threats. The project will involve the geoscience community, but also biologists, archaeologists, historians, meteorologists and astrophysicists.

Project No. 499 - Evolution of Ecosystems and Climate in the Devonian (P. Königshof, Germany, J. Lazauskiene, Lithuania, E. Schindler, Germany, Volker Wilde, Germany and N. Yalçin, Turkey)

The Devonian was a critical period with the rapid development of plants and animals on land, rapid climate change from greenhouse to icehouse conditions, with resultant influence on sedimentation and biodiversity in both the terrestrial and marine realms. The project will include specific case studies from international sites, involving co-operation from workers in many disciplines, such as sedimentology, palaeontology, stratigraphy, palaeoclimatology, palaeogeography, geochemistry, palaeooceanography, and structural geology, in collaboration with the Subcommission on Devonian Stratigraphy (SDS). The results of the project will contribute to the understanding of the development of economically important deposits in Devonian rocks including: 1) clastic and carbonate sequences that are source and host rocks for petroleum and/or natural gas and may carry important groundwater resources; 2 ) hematitic iron ores, sedimentary lead-zinc deposits, and evaporites (e.g., anhydrite, gypsum). The results of the project may be beneficial for the participating developing and fast-developing countries. Studies of the evolution and interaction of Devonian marine and terrestrial ecosystems may contribute to the understanding of forces driving climate and ecosystems today and in the future. Understanding Devonian climate dynamics may help refine modern climatic models.

Project No. 500 - Westerlies and Monsoons: Impacts of Climate Change and Variability on Dryland Environments, Hydrology, and People (D. Thomas, United Kingdom)

The project has three main aims: 1) to enhance the welfare of dryland societies by better understanding of driving forces of climate change and variability, environmental change and key resource availability over timescales ranging from millennia to subdecadal; 2) to investigate the dynamics of key dryland landscape and resource elements, especially hydrological dynamics and aeolian system dynamics, and their impacts on and interactions with the human use of drylands through the Quaternary (last 11,500 years before present) and their impacts on and interactions with the human use of drylands; by understanding hydrological responses to dryland climate change at millennial to subdecadal timescales; identification of resultant ecosystem changes, better understanding of dryland history through the Quaternary, and refinement of understanding human responses to dryland changes at millenial to subdecadal timescales; and 3): to enhance capacity in cutting edge dryland science and to provide a significant dryland input to the co-IGCP CHANGES initiative by evaluation and assessment of the utility of different palaeoenvironmental proxies and chronometric techniques to dryland settings, exchange of research ideas, methods and results between different scientific groups and communities, including interdisciplinary cooperation, and enhancement of developing world scientific capacity in dryland research, including the training of graduate students and other highly qualified personnel.

\section{Project No. 523 - GROWNET - Global Groundwater Network} (Shrikant Daji LIMAYE, India, and A J Reedman, UK)

Groundwater management includes exploration, assessment, sustainable utilization and protection of quality and quantity of groundwater. In many developing or low-income countries, groundwater is becoming over-exploited, polluted and scarce. However, in small rural watersheds, there are a few examples of better manage- ment, through devoted work of some NGOs with participation of local people. In urban areas, there are examples of roof water harvesting and recharging of aquifers. This project proposes to disseminate the success stories and experiences of ground water management through development of a website (GROWNET) and a Newsletter; to arrange regional meetings of experts involved to discuss the methodologies, success, and shortcomings. We intend GROWNET to be an effective, transparent, authentic and gendersensitive network for dissemination of information on the best practices of groundwater management and capacity building in South and South-East Asia, Sub-Saharan Africa and in Latin America.

\section{Example of an especially successful IGCP project emphasizing basic research}

Project No. 440 - Rodinia Assembly and Breakup (S. Bogdanova, Sweden; Z.-X. Li, Australia; H. Kampunzu, Botswana; R. Unrug; USA; C. McA. Powell, Australia)

The project aimed to map the distribution of the currently dispersed pieces of the Late Mesoproterozoic-Early Neoproterozoic Rodinia Supercontinent (predecessor of the Gondwana Supercontinent) and, through interdisciplinary studies, document the Mesoproterozoic accretion and the Neoproterozoic breakup of that supercontinent. It was also intended to determine whether the Palaeoproterozoic cratons originated by breakup of an older, pre-Rodinia supercontinent, or were independent fragments of continental crust. The final output of the project will be the publication of the Geodynamic Map of the Rodinia Supercontinent Assembly. The reconstruction of the Rodinia Supercontinent will lead to the interpretation of the current distribution of fragments of formerly continuous Mesoproterozoic metallogenic provinces, providing a strong conceptual background to mineral exploration programmes in several continents and for the overall evolution of the Earth. The foundations of the project were laid in the results of IGCP Project 288, Gondwanaland sutures and fold belts. Project 440 is one of the most successful projects of IGCP and has resulted in about 50 papers per year in high-impact factor peer-reviewed journals, such as Precambrian Research, Geology, Earth and Planetary Science Letters, J. Geological Society of London, and Gondwana Research. In addition, several books and field excursion guides have been produced. Over 300 scientists from more than 40 countries participated in this project. Developing countries, including those from Latin America, Africa, the Middle East and Asia, were well-represented in the project. Its activities involved scientists from all continents-this was a true IGCP project. The project has been very successful in the promotion of interaction between different disciplines in the Earth Sciences, notably, geology, geochronology, and palaeomagnetism. The project has also introduced and promoted post-graduate training and collaboration in the utilization of research facilities (e.g. rock-dating facilities - mass spectrometers) between scientists from different countries and institutions. This project has helped in the development of geochronological techniques, especially single zircon dating techniques, e.g., SHRIMP and evaporation techniques. Another outgrowth of the project has been improvement of the precision of palaeomagnetic analytical techniques. The project initiated the incorporation of "plumes and superplumes" into geodynamic models for the dispersal of Proterozoic supercontinents (i.e., Rodinia and Gondwana). The most conspicuous product of this project is the Geodynamic Map of Rodinia Supercontinent Assembly, which is in the final stages of publication. 